\title{
TAMANHO DE PÊNIS. INQUIETAÇÕES MASCULINAS E SOLUÇÕES
}

\author{
Alfredo Romero ${ }^{1}$; José Roberto Stipp ${ }^{2}$; Inês Cavalieri ${ }^{3}$; \\ Murilo Caldeira Ribeiro ${ }^{4}$; Sara Modenez ${ }^{5}$
}

\section{SIZE OF PENIS. MALE ANXIETIES AND SOLUTIONS}

Resumo: Na história da humanidade o tamanho do pênis foi considerado pelas diferentes culturas como símbolo de poder e virilidade. Nos anos 60, quando os cirurgiōes pediátricos operaram crianças com micropênis ou malformações congênitas, lançaram-se as bases do que seria nas décadas seguintes a divulgação de tratamentos para patologias, traumatismos que encurtavam ou afinavam o pênis, ou indivíduos normais que desejavam o aumento em comprimento ou grossura. Este enfoque provocou controvérsia acirrada por posicionamentos contrários ou favoráveis a estes. Neste trabalho, expomos as inquietações e possíveis soluções para os portadores desta entidade. Realizamos uma revisão das opiniōes de renomados especialistas que opinaram contrária ou favoravelmente a estes procedimentos. Sabemos que não é um capitulo fechado da medicina, mas apenas o inicio de uma discussão mais abrangente para que os profissionais da área da sexualidade humana possam ao menos, orientar aqueles que têm este sofrimento como fator limitante das suas vidas.

Palavras-chave: Tamanho de pênis; cirurgia; alongamento; ligamento suspensório; engrossamento.

\footnotetext{
Abstract: In the history of human kind the size of penis has been considered as a symbol of power and of manhood. In the sixties pediatric surgeons when operating children having micropenes or having congenital malformations,

1 Biomédico, médico, cirurgião vascular, mestre em sexologia. Diretor do Instituto Brasileiro para Saúde Sexual (IBRASEX0). e-mail:alfredoromero@terra.com.br

Médico, Cirurgião Vascular. IBRASEX0. e-mail: drstipp@ig.com.br

Psicóloga e Mestre em Sexologia, IBRASEX0. e-mail: ines.cavalieri@terra.com.br

Médico, Cirurgião Plástico, IBRASEX0.e-mail: info@murillocaldeira.med.br

5 Médica. IBRASEXO. e-mail: sarasolm@gmail.com
} 
they gave basis to the spread of treatments for pathologies or traumatisms shortening or reducing penis, or treatments for normal individuals who wanted lengthening or enlargement of their penes. The latter provoked controversy exasperated by contrary or favorable opinions. In this work we exposed the anxieties of those who wanted such treatments and possible solutions for them. We reviewed the opinion of renowned specialists who were against or in favor of these procedures. We know this is not a final chapter in medicine but the beginning of a more including discussion instead so that the professionals in the area of human sexuality at least can guide those patients who feel their lives are limited because of their anxieties.

Keywords: Penis size; surgery; lengthening; suspensory ligament; enlargement.

Poucas vezes ao longo dos últimos anos, observamos um título de conferência que denotasse com maior exatidão, a realidade do assunto a ser abordado. Segundo HOLANDA, (1988): "[...] inquietação define-se como falta de quietação; falta de sossego; excitação; agitação". Esta definição provavelmente é a que melhor caracteriza o homem que sofre, ou pensa sofrer, de algum problema sexual relacionado ao tamanho do pênis em comprimento e grossura em ereção ou flacidez.

Não temos dúvida que discorrer sobre as inquietaçōes do homem com essa queixa, é tarefa muito mais amena, do que propor soluções para este tipo de problema. Não porque as soluçōes não existam, mas pela terrível controvérsia que tais procedimentos provocam entre as mais diferentes especialidades, que se dedicam ao tratamento do homem insatisfeito com o tamanho do seu pênis. Diga-se de passagem, nem sempre os profissionais que opinam a respeito do assunto, possuem experiência no uso dos diferentes métodos utilizados para este tratamento, no entanto, permitem-se opinar sobre uma área que engloba aspectos psicossexuais tão profundos, por que inclusive afetam profissionais da área da saúde, entre eles, também os terapeutas sexuais, lembrando-nos de que somos humanos.

Masters \& Johnson, entre as falácias fálicas mencionam que:

[...] é largamente aceito o conceito de que quanto maior é o pênis mais eficiente é o macho numa conexão coital. O tamanho do órgão sexual masculino, tanto no estado flácido quanto no erecto tem sido considerado por muitas culturas, como capaz de refletir a bravura sexual do indivíduo masculino (MASTER \& JOHNSON, 1984, p. 158) 
$\mathrm{Na}$ mesma obra, os autores mencionam que:

[...] a vagina é infinitamente distensível do ponto de vista clinico e que a mulher pode apresentar dificuldade na acomodação de um pênis particularmente grande, quando a introdução ocorre nos primórdios da fase da excitação. Porém, tanto um pênis grande quanto o pênis pequeno terão uma acomodação vaginal total. É muito interessante quando percebemos que as mulheres apreciam relativamente o tamanho do pênis, e não é esta a parte da anatomia masculina que elas mais valorizam. (ibid., p. 160)

Em uma pesquisa realizada no Jornal Village Voice de Nova York, foi solicitado a 100 homens que indicassem as partes do corpo que, em sua opinião, atraiam mais as mulheres. Ao mesmo tempo solicitou-se a 100 mulheres que expressassem as suas preferências quanto às características físicas masculinas que considerassem mais atrativas. Os homens opinaram que as mulheres admiravam sobre maneira, braços musculosos e um pênis grande no tamanho. No entanto, as mulheres declararam que estas características as repeliam e citaram outras partes do corpo como atributos mais admirados nos homens. Citaram nádegas pequenas e sensuais (39\%); um corpo esbelto (15\%); os olhos (11\%), e apenas (2\%) das mulheres expressaram que o pênis é a parte mais atrativa no homem (ENCICLOPÉDIA DE LA SEXUALIDAD, 2002, p. 115).

Estes mesmos autores mencionam que os critérios estéticos para a genitália masculina, encontram-se vinculado ao tamanho do pênis, em numerosas sociedades, e que um pênis de grande tamanho é geralmente objeto de admiração. Nossa sociedade não foge a esta tradição, crença que converteu-se para muitos homens em motivo de angústia como refletem as inúmeras consultas sexológicas geradas por este tema, independente dos estudos que demonstrem que para as mulheres, o tamanho do pênis não é demasiadamente importante.

Pensam os autores Masters \& Johnson (op. cit., 1984) que a vagina se adapta a qualquer pênis por pequeno que seja. $O$ fato de a vagina ser mais sensível na entrada do que na profundidade, faz desnecessária uma excessiva longitude, já que os pênis pequenos aumentam mais o seu tamanho durante a ereção que os pênis maiores. Assim sendo, as comparaçóes do pênis em estado flácido não indicam o tamanho que alcançará em ereção, e por fim que uma maioria de mulheres aprecia mais a qualidade do que a quantidade, e mais ainda, quem está por traz do pênis, do que o seu tamanho em si. Mas, como pensa o homem que imagina ter um pênis pequeno, independente do tamanho real? O que leva um indivíduo a se comparar com os outros em um chuveiro coletivo, vestiário, ou numa praia, ou piscina? O que provoca na mente dessas 
pessoas a incapacidade ao longo da vida para uma relação a dois? Qual a motivação que leva um homem a tentar o suicídio, quando considera que seu pênis não tem as dimensões adequadas?

E o caso de um colega cardiologista, preocupado com o dia em que morrer, quando alguém irá trocar suas vestes e verá que seu pênis em flacidez não tem a metade do tamanho que tem em ereção, e por isso deseja aumentar o comprimento do seu pênis? O que leva um homem a se manter casto até os 46 anos de idade por considerar seu pênis ridiculamente pequeno? Ou a um jovem de 18 anos a ser usuário de drogas lícitas e ilícitas, largar a escola, brigar diuturnamente com pai e mãe porque são loucos de não entender o seu caso, tanto quanto os profissionais que consultou e não deram a solução para seu problema?

O que pensa um médico que aos 70 anos de idade e por toda sua vida sexual praticou o coito de cueca e apenas colocando o pênis pela abertura da mesma, com a luz apagada, tendo pensado inúmeras vezes em suicídio devido ao tamanho reduzido do seu pênis? E que dizer daquele psicólogo, experiente que ao tomar banho com a filhinha de 6 anos de idade, a mesma diz: "olha o pintinho do papai", dirigindo-se a mãe, e a partir desse momento o pai passou a procurar desesperadamente por uma solução para o tamanho do pênis pequeno? E que pensará aquele jovem que chegado o momento do exame médico no serviço militar, corta a sola do pé, para não ter que submeter-se ao exame e se expor na frente dos colegas da mesma idade, por achar o seu pênis pequeno?

Há alguns anos tentamos responder a essas perguntas: o que leva um homem a pensar que seu pênis tem dimensões reduzidas. Apesar da literatura médica ser extensa na classificação dos distúrbios psiquiátricos, psicológicos e etc, dificilmente assinalam posicionamentos específicos em relação a este problema, fazendo com que muitos desses homens, que fizeram tratamentos sérios, em instituições sérias continuem vivendo tais inquietações.

A experiência nos faz perceber a angústia que tais situações provocam na vida de relação destes homens, que se acreditam tão pouco dotados pela natureza do ponto de vista psico-sexológico, principalmente, ao perceberse que a grande maioria são homens perfeitamente normais, e que tem o seu pênis com dimensões médias ou até com grandes. Porém, os conflitos intra e interpessoais são muito maiores que a dimensão dos seus falos.

Poucos homens possuem realmente um micropênis. No Instituto Brasileiro para Saúde Sexual, em São Paulo e no Ambulatório de Sexologia do Instituto 
de Ginecologia da UFRJ, durante a realização de exames para diagnóstico de disfunção erétil (ROMERO \& CANELLA, 2003), ejaculação precoce (ROMERO, 2003), alguns pacientes apresentavam também como queixa o tamanho de pênis. Realizamos a medição do pênis em todos os pacientes que tiveram ereção plena durante o teste fármaco induzido com uso de droga vasoativa. A medição foi feita com fita métrica do ângulo peno pubiano ao meato uretral, e a circunferência na base do pênis ao nível do ângulo peno pubiano e na região distal no sulco bálano-prepucial, em flacidez e ereção, em comprimento e grossura em 879 pacientes com idade média de 42,74 anos, idade mínima de 18 anos e idade máxima de 83 anos. A média do pênis em comprimento flácido foi de $9,45 \mathrm{~cm}$; o comprimento máximo flácido $16 \mathrm{~cm}$ e o comprimento mínimo flácido $2,0 \mathrm{~cm}$. A média da circunferência foi de $9,34 \mathrm{~cm}$, sendo a circunferência flácida mínima $5,0 \mathrm{~cm}$ e a circunferência máxima flácida $13,5 \mathrm{~cm}$.

A média do comprimento ereto foi de $13,97 \mathrm{~cm}$, sendo o comprimento ereto mínimo $5,0 \mathrm{~cm}$ e o comprimento ereto máximo $21,0 \mathrm{~cm}$. A média da circunferência em ereção proximal foi de $12,12 \mathrm{~cm}$, sendo a circunferência em ereção proximal mínima $8,0 \mathrm{~cm}$ e a circunferência em ereção proximal máxima $17,5 \mathrm{~cm}$. A média da circunferência em ereção distal foi de $11,94 \mathrm{~cm}$, sendo a circunferência em ereção distal mínima $8,0 \mathrm{~cm}$, e a circunferência em ereção distal máxima $17,5 \mathrm{~cm}$.

É interessante observarmos nestes dados, que as dimensões penianas encontram-se de acordo com inúmeros trabalhos publicados por diversos autores (GARAT Y RUIZ DE TEMIÑO apud MONSENY y ARRONDO, 1994, p. 775; SANTOS, 1996; SCHONFELD \& BEEBE, 1942; WESSELLS, LUE \& MCANINCH 1996; MAIZELS, ZAONTZ, DONOVAN, BUSHNICK \& FIRLIT, 1986; HINDERER Y ESPINOSA, 1997; STUBBS, 1997; FELDMAN \& SMITH 1975; MARZANO, 2002; BURMAN \& KELLY, 1996; ALTER, 1995; ROOS \& LISSOOS, 1994). Podemos afirmar por estas medidas que a média de comprimento do pênis flácido é de $9,45 \mathrm{~cm}$, a circunferência média 9,34, a média do comprimento ereto $13,97 \mathrm{~cm}$, a média da circunferência proximal em ereção $12,12 \mathrm{~cm}$ e a média da circunferência distal 11,94 cm. Penso que seja de suma importância guardar esses números médios, para que ao consultarmos um paciente, possamos dispor de dados reais de pesquisa para efetivar um comparativo com o pênis do paciente.

Em nossa experiência clínica, percebemos que a maioria dos homens que procuram atendimento profissional, com queixas de tamanho de pênis, o faz preocupada com o comprimento do pênis em flacidez e, os que mostram 
preocupação com a grossura do pênis, esta encontra-se relacionada ao estado de ereção para a atividade sexual, pensando que ao possuir um pênis maior na sua circunferência, isto dará maior prazer a sua companheira.

A esmagadora maioria dos homens que se preocupam com o tamanho do pênis flácido, sofre a chamada Síndrome do Vestiário (CARLSON, ARRONDO, KIRBY \& GOLDESTEIN, 1999; ROMERO, 2002). Estes homens não se expõem a outros homens, ou, se quer, às suas parceiras durante a atividade sexual, não usam sungas na praia ou na piscina e raramente usam vestes que possam marcar sua área genital. São homens que frequentemente consultaram vários médicos com esta queixa e relatam insatisfação nas consultas realizadas, por considerarem que o profissional não valorizou sua queixa, ou levou a mesma, para o lado jocoso, inclusive com comentários pejorativos sobre a não necessidade de tratamento, já que consideravam-no um homem normal. Outros foram encaminhados a um psicólogo e após algumas sessões de terapia abandonaram o tratamento proposto, já que não percebiam melhora no tamanho dos seus falos.

\section{Soluções para os homens que se preocupam com o tamanho do seu pênis}

Como tratar um homem cujo pênis: micro, pequeno, médio, grande ou macro pênis, tem o perfil relatado anteriormente? É uma resposta extremamente difícil do ponto de vista médico-psiquiátrico ou psicológico, qualquer que seja a abordagem, provavelmente, falharemos.

[...] Infelizmente, nem sempre quando uma pessoa procura um profissional de saúde, este tem a solução do problema, tendo em vista que esta é uma área nova de especialização e muitos ainda não se encontram preparados e atualizados na clínica de disfunção sexual. A premissa, no caso de homens, é que o urologista seja o médico em condições de tratar disfunção sexual (erétil, ejaculatória ou estética), porém, estudos mostram que 30\% destes profissionais - máximo - têm algum tipo de conhecimento para orientar esta população. Como o princípio básico da sexologia é multidisciplinar, o trabalho em equipe é básico e necessário, pois só assim estaremos realmente capacitados a atender aos pacientes disfuncionais, pois em nosso conceito um médico sozinho dificilmente terá a capacidade e conhecimento técnico suficiente para diagnosticar e tratar um paciente em áreas tão diferentes como a psicologia, neurologia, cirurgia vascular, endocrinologia, cardiologia e urologia, especialidades que fazem interface direta com os sistemas que compõem o mecanismo sexual. No caso de mulheres, quando consultam, uma ou duas vezes por ano seu ginecologista, e mencionam que convivem com algum tipo de disfunção sexual, 
delas mesmas ou dos maridos, normalmente são encaminhadas a um psicólogo. No entanto, a maioria destes profissionais não teve sequer nos currículos escolares, ao menos uma disciplina que enfocasse as disfunções sexuais masculinas ou femininas. Portanto, podemos afirmar que a grande maioria dos profissionais, médicos e psicólogos em seus cursos de graduação, em geral não tem formação específica para a clínica de problemas sexuais. Assim, a obtenção de conhecimentos específicos na área, irá requerer para a grande maioria, uma especialização após os cursos de graduação. Aliás, como ocorre em todas as outras especialidades. (ROMERO 2002, p.22-23).

\section{Segundo Andrade-Silva:}

[...] mesmo na época atual, em que se acredita estar vivendo uma maior liberdade sexual, a adequação e o desempenho a uma performance ajustada às exigências de padrões determinados como normais persistem, propiciando fortes sentimentos de inferioridade especialmente naqueles, que não conseguem se considerar como fazendo parte do "mundo dos normais".

O domínio fálico do pênis foi e ainda é motor de poder, força, virilidade e competência e todo homem, recebeu mensagens claras ou sutis, de que é um privilégio ser portador de um. No entanto tal distinção acarreta a pesada responsabilidade de ter que ser um digno representante do mundo dos homens - onde todas as qualidades atribuídas ao pênis, serão diretamente vinculadas e cobradas ao dono dele. Assim quando um homem tem ou acredita ter, um pênis pequeno, ou fracassa em ter ou manter uma ereção, seu auto-conceito de ser, facilmente pode encontrar-se inferiorizado, fragilizado e repleto de sentimentos de menos valia. Percepções que não ficam restritas ao órgão em si, mas interferem na estrutura deste ser como um todo, desenvolvendo a constituição de percepção negativa de si mesmo e comprometendo as relações interpessoais. É preciso que se entenda que os problemas sexuais, podem advir de comprometimentos orgânico funcionais, psicológicos e socioculturais e que em vários casos, apresentam-se também como causas mistas - quando, por exemplo, um pequeno comprometimento orgânico, poderá se tornar intenso, em função de constituições psicológicas comprometedoras ou pressões sociais constantes. Um diagnóstico diferencial aprofundado e adequado será a porta para o sucesso de qualquer procedimento clínico a ser efetivado (ANDRADESILVA, 2002, apud ROMERO, 2002, p. 15).

Temos a convicção de que se dermos a estes homens o mínimo de atenção e seriedade, ao ouvirmos o relato das suas queixas, estaremos contribuindo para que eles se sintam respeitados e percebam no profissional que os escuta, seriedade no atendimento do seu problema. Torna-se indispensável, um exame físico para avaliar os mais diferentes parâmetros que podem estar contribuindo para sua queixa. É necessário que cada um desses homens, seja submetido a um teste de ereção fármaco-induzido, com estímulo visual erótico, e com o uso de drogas pró-eréteis orais ou com drogas vasoativas intracavernosas 
(ROMERO \& CANELLA, 2003), a fim de mensurarmos o pênis em comprimento e grossura em estado de flacidez e ereção. Há que verificar a presença ou não de fimose ou de cirurgias prévias que por ventura tenham afetado a exposição do pênis, como no caso da postectomia, em que alguns cirurgiōes, acabam retirando pele em excesso, fazendo com que os ângulos peno pubiano ou peno escrotal avancem sobre a haste peniana, escondendo uma porção considerável do pênis em estado de ereção, e retraindo-o excessivamente em estado de flacidez.

Deve ser verificada a presença de gordura supra-púbica, em indivíduos obesos e quando este quadro está presente, orientar o paciente sobre a perda de peso, exercício físico e alimentação adequada - orientação higienodietética, para poder ter uma exposição melhor do pênis.

É importante a verificação de patologias como: curvaturas congênitas ou adquiridas, como a doença de Peyronie, o que provoca uma curvatura acentuada com diminuição no comprimento e na grossura do pênis; a presença de hipospádia ou epispádia, também contribui para possíveis curvaturas e encurtamento do pênis. Uma vez feito isto, sem dúvida alguma, o paciente estará percebendo, que o profissional que o atende, está no mínimo, empenhado em diagnosticar e ajudar a resolver o problema que o aflige. Por outro lado, este profissional deve mostrar segurança nas suas colocações, explicar a fisiologia da resposta sexual humana, masculina e feminina, para que o paciente perceba que, mesmo se ele tiver um pênis pequeno ou micro pênis, poderá satisfazer sua parceira. Explanar sobre a variedade de motivações que interferem na atração sexual entre homem-mulher. E que para muitos, sexo é parte de uma relação mais ampla, onde antes que se concretize a atividade sexual propriamente dita, forma-se na maioria dos casais vínculos afetivos, que também contribuirão para a percepção da qualidade da relação sexual que venham a ter.

Recomenda-se ao profissional, que pretende orientar um paciente destes, disponibilização de recurso áudio-visual, para melhor ilustrar as suas explanaçôes, e dizer ao paciente, que seu pênis é normal, que poderá satisfazer a maioria das parceiras. Aliás, é importante salientar que raramente uma parceira reclama do tamanho do pênis do parceiro.

Em nossa experiência clínica, mesmo depois de transcorridas todas essas etapas da consulta, o que demora de 2 a 3 horas, (haja vista a necessidade de se utilizar drogas vasoativas intracavernosas), fazendo-se necessária, às vezes, à deflação induzida; alguns pacientes continuam desejando ter o pênis aumentado de tamanho. 
Em 1997, o Conselho Federal de Medicina, normatizou através da Resolução 1478/97 como experimental o procedimento cirúrgico para o aumento peniano e o tratamento cirúrgico da Ejaculação Precoce. Normatização esta que foi considerada inconstitucional em primeira instância pela Justiça Federal em ação interposta pela Sociedade Gaúcha de Andrologia, solicitando a suspensão ou anulação de tal Resolução em 21/02/2002. O mérito do pedido foi julgado procedente em primeira Instância encontrando-se atualmente em segunda Instância.

Em setembro de 2000, a ISIR (INTERNATIONAL SOCIETY FOR IMPOTENCE RESEARCH) fez um levantamento através do corpo editorial do ISIR - News Bulletin, entre as diferentes categorias de profissionais no campo da sexualidade. Opiniōes estas que parecem importantes devido à representatividade dos profissionais que dela participaram, e pela abrangência de representaçóes distribuídas nos 5 continentes. Vários profissionais expressaram suas opiniōes, favoráveis ou não, quanto aos procedimentos para o tratamento de pacientes com queixa de tamanho de pênis. Para Buvat e Lemaire (apud ISIR, 2000, p. 13), o alongamento peniano e a cirurgia de aumento de circunferência estão atraindo mais e mais homens. Contudo, tanto seus resultados objetivos quanto as implicações éticas ainda são debatidas. Burman (apud ISIR, 2000, p. 14) tem uma larga experiência nessas cirurgias e, relata que os cirurgiōes pediátricos descreveram há mais de duas décadas, a secção dos ligamentos fundiformes e suspensório do pênis para correção de micro-pênis congênito, assim como os cirurgiões plásticos utilizam os enxertos autólogos lipoaspirados e de gordura dérmica para mudança de contorno. Menciona que os cirurgiōes plásticos têm melhor domínio do que os urologistas para a realização da cirurgia de aumento peniano, porém, se eles o desejarem, podem dominar as técnicas de faloplastia. Relata, ainda, que a maioria dos pacientes de faloplastia são heterossexuais, e que tem um pênis dentro da média de comprimento, portanto, seriam homens normais, e que mesmo assim, isso não muda sua forma de pensar e querem fazer a operação. Propõe como método alternativo para aumento da circunferência, derivado alodérmico de cadáver, o que produziria resultados altamente satisfatórios em mãos experientes. Afirma que não há interferência das técnicas na micção, fertilidade, ereção ou ejaculação, perda de sensibilidade, instabilidade, ou inchaço na base do pênis, mudança no ângulo erétil, na consistência ou no sentir do pênis.

Schouman (apud ISIR, 2000, p. 14), com experiência de 15 anos em cirurgia de alongamento em micro-pênis real, afirma que a maioria dos pacientes tem pênis de tamanho normal e solicitam uma faloplastia estética para um pênis 
grosso e longo no estado flácido, e até $25 \%$ dos candidatos são homo ou bissexuais. Utiliza a secção do ligamento suspensório e a técnica VY para alongamento e aumento de circunferência por lipoenxerto, quando necessário realiza a lipoaspiração pubiana. Consegue aumento de 2 a $3 \mathrm{~cm}$ de diâmetro no estado flácido. Assim como BURMAN (op.cit), afirma não haver modificação do ângulo penopúbico nem da ereção ou da fertilidade. Diz que o aumento de comprimento no estado ereto é pobre, mas notável para a largura. Como complicação relata necrose do retalho púbico bem como reabsorção da gordura. Não recomenda tais cirurgias para pacientes dismórficos corporais, para o que recomenda aconselhamento psicológico prévio. Pensa que pode ser um procedimento realizado tanto por cirurgiōes plásticos quanto por urologistas, desde que estes aceitem executar a cirurgia com finalidade não patológica. Belgrano (apud ISIR, 2000, p. 15) relata a existência de muitos estudos sobre o problema e os diferentes tipos de correçôes cirúrgicas e tenta tipificar a linguagem para uso universal nos quatro tópicos seguintes: 1. O "verdadeiro micro-pênis" é uma condição que deve ser diagnosticada logo após o nascimento. O pênis esticado é mais do que 2 desvios do padrão abaixo do comprimento médio. $\mathrm{O}$ comprimento crítico abaixo do qual se pode definir micro-pênis é de $2,5 \mathrm{~cm} ; 2$. Pênis enterrado ou escondido: condição mais freqüente em crianças, mas não infreqüente em adultos obesos. O comprimento peniano e a circunferência são normais ou ligeiramente curtos, mas o pênis é coberto por um enchimento de gordura anormal. Os outros dois tipos devem ser incluídos na dismorfofobia por razōes estéticas ou funcionais: 3. No "tipo estético" o paciente não aceita o tamanho de seu pênis, que é normal, particularmente no estado flácido; compara seu pênis com o de outras pessoas, da mesma idade, e acredita que o seu é menor. 4. No "tipo funcional" acredita que o comprimento é normal, mas a circunferência não o gratifica durante a ereção. Orienta para que no verdadeiro micro-pênis a terapia seja obrigatória, assim como o pênis enterrado também deve ser tratado cirurgicamente; na dismorfofobia, a cirurgia seja considerada como plástica estética com as mesmas implicações éticas da cirurgia plástica. Relata que complicações como necrose de gordura e formações de cicatrizes ou retração do pênis podem ocorrer. Acredita que a técnica de colocação de enxertos de safenas bilaterais como descrito por Austoni (apud ISIR, 2000, p. 16) pode ser utilizada para aumento da circunferência peniana. Recomenda, ainda, avaliar com precisão os aspectos médico-legais.

Tan (apud ISIR, 2000, p. 15) menciona aumento peniano em 1335 pacientes em que o aumento de comprimento médio foi de $2,93 \mathrm{~cm}$, a circunferência $4,5 \mathrm{~cm}$ e a taxa de satisfação dos pacientes de $95 \%$. Menciona que as compli- 
cações variaram de 1 a 2,6\% e poderiam ser devastadoras incluindo dor persistente, pênis pendente baixo, disfunção erétil e trauma emocional grave quando as expectativas não são cumpridas. Como indicações absolutas para o aumento peniano, o autor menciona micro-pênis, pênis oculto ou enterrado, doença de Peyronie, pacientes com pênis curto e pênis amputado traumático. Deve o paciente receber aconselhamento pré-operatório detalhado, avaliação psicológica e avaliação da motivação e das expectativas do mesmo, pois, se realista, evitará insatisfações subseqüentes.

Austoni, em 1999, propóe técnica própria com o uso de enxertos de veia safena bilateral para aumento da circunferência, esta técnica é similar à idealizada por Romero (1992 e 2000) com o uso de enxertos vasculares bilaterais em pacientes portadores de próteses penianas. Finaliza Austoni (op. cit) recomendando que as técnicas devam ser praticadas por cirurgiōes altamente experientes com habilidade comprovada em procedimentos plásticos de reconstrução.

Para Dabees (apud ISIR, 2000, p. 19) é justa uma avaliação quanto a aceitação da idéia de que alguns homens podem precisar de cirurgia estética. Menciona que até mesmo em urologia a cirurgia de hipospádia da metade distal da uretra é estética ao invés de funcional e não vê porque é errado tratar esteticamente o homem. Afirma que a sociedade moderna revela mais o corpo a cada ano. Por que deixar alguns homens esconder-se e envergonhar-se por seus pênis? Indica a cirurgia para pacientes com micro-pênis, pois se aumentar 2 ou 3 $\mathrm{cm}$ a um pênis de 5 a $8 \mathrm{~cm}$, isto constituirá aumento de 30 a $50 \%$, mas se fizer isso por um pênis de 10 ou $12 \mathrm{~cm}$ terá menos que $20 \%$ de aumento e não será apreciado pelo paciente. $\mathrm{O}$ aumento peniano ainda está em sua infância, como no recém nascido, que faz muito barulho e não tem uma forma final. Relata que não se deve condená-lo por causa dos seus curtos resultados e sim pesquisar a melhor forma de fazê-lo no paciente indicado.

Christiansen (2000) propõe que um adulto com informação qualificada durante a adolescência, poderia poupar muitas tragédias de jovens mais tarde. Relata que a maioria dos homens quer se submeter ao alongamento peniano para aumentar sua auto-imagem (79\%), enquanto que $14 \%$ precisam da cirurgia a partir de desajustamento funcional e apenas $6 \%$ sofrem de um defeito congênito. 59,3\% dos clientes estão dentro do grupo de 35 a 50 anos. Segundo a sua experiência, os problemas físicos se iniciam na escola onde as diferenças de tamanho peniano são focalizadas de maneira exacerbada no chuveiro comum o que poderia induzir a perdedores e vencedores. É ali que alguma informação qualificada de um adulto informado nesse estágio 
da vida poderia poupar muitos jovens de futuras tragédias. Menciona que a maioria dos homens não consulta suas parceiras sobre sua opinião a respeito do tamanho de seu pênis. Em sua prática, tenta desencorajar seus pacientes a fazer alongamento peniano. Porém, algumas vezes, a saúde mental do paciente pode estar tão fortemente ligada à sua auto-estima que a cirurgia peniana pode ser executada para se evitar uma catástrofe pessoal.

Para Krishnamurti (apud ISIR, 2000, p. 20) a confusão desnecessária levantada por esta questão deve-se principalmente as desventuras de alguns cirurgiōes super entusiasmados e ao furor levantado por seus pacientes litigantes. Isso não significa que todo o capítulo deva ser fechado. Se isto nasce na mente, a necessidade de se aumentar o pênis pode ser compreendida com mais empatia e deve ser oferecido tratamento tanto para homens necessitados quanto para os gananciosos. O autor questiona: "devemos lembrar que existem homens que optam por operações plásticas em muitas outras partes do corpo, porque o pênis teria que ser uma exceção?”. Kim (apud ISIR, 2000, p. 20) relata que o homem percebe facilmente que o tamanho peniano importa e insiste que um aumento sob o símbolo da masculinidade eleva também seu ego. As técnicas podem gerar complicações potenciais demandando custos e tempo dos pacientes, por isto aconselha o acompanhamento psicológico antes da cirurgia, avaliação da motivação e das expectativas dos pacientes. Indica a cirurgia quando o pênis ereto cai abaixo de dois desvios padrão da norma. Gingell (apud ISIR, 2000, p. 20) menciona a necessidade da avaliação psiquiátrica e psicológica dos homens que desejam tais tratamentos e relata: o único ganho certo obtido pela operação mais comumente empregada de VY é o financeiro pelo cirurgião.

Amar (apud ISIR, 2000, p. 21) indica a cirurgia, nunca negando o desejo dos pacientes, tendo uma longa conversa com os mesmos, explicando-lhes os riscos e benefícios. Pensa que $10 \%$ deles são operados. Nunca vê os pacientes novamente e diz sempre: "melhor ter um curto ocupado trabalhando do que um longo ocioso". Para Sharlip (apud ISIR, 2000, p. 21) estas técnicas cirúrgicas não são confiáveis. As cirurgias de aumento de circunferência podem ser conseguidas com algum sucesso, mas o verdadeiro alongamento do pênis é impossível. Quase todos os pacientes não são realistas em suas expectativas e nos resultados dessas cirurgias. Quando a auto-estima de um homem é determinada pelo comprimento de seu pênis, o problema certamente não está em sua genitália.

Meuleman (apud ISIR, 2000, p. 21), que não está mais fazendo a operação de alongamento peniano, apesar de ter feito muitas, ficou bastante desapon- 
tado com os resultados, e o mesmo sentiram seus pacientes, pois o efeito das técnicas é no estado flácido. Freqüentemente a origem do problema é uma má adaptação psicossocial que necessita de uma profunda abordagem psicossexual. Recomenda o alongamento para homens que realmente tem um pênis muito curto e que esta cirurgia deve ser realizada por um cirurgião familiarizado com transposições femininas para masculinas.

Junemann (apud ISIR, 2000, p. 22) refere-se a Wessells, Lue \& Mcaninch (1996) os quais estimam que 10.000 homens submeteram-se a alongamento e aumento de circunferência desde a introdução do procedimento cirúrgico. Pensa que a cirurgia estética da genitália masculina é lógica e aconselhável e que a indicação correta para esse tipo de tratamento cirúrgico é mais importante do que o aspecto ético. Questiona se é aconselhável administrar-se um problema psicológico com intervenção cirúrgica. Opina que a técnica operatória só pode ser realizada com indicação clara, se não, não deve ser realizada em um órgão saudável com alto risco de prejuízo funcional. Pondera que o alongamento cirúrgico do pênis pode exercer um efeito positivo sobre o bem estar psicológico de determinados pacientes e desaconselha à execução de tais cirurgias até que existam estatísticas objetivas, adequadas e uma indicação padronizada.

Krane (apud ISIR, 2000, p. 22) pensa que os tratamentos devem ser realizados em pacientes com pênis patologicamente pequenos. Glina (apud ISIR, 2000, p. 22) relata resultados modestos e muitas complicações dentre as quais o encurtamento peniano, cicatrizes terríveis e infecção peniana. Relata um paciente que o consultou solicitando uma segunda opinião, o qual cometeu suicídio após a cirurgia de alongamento peniano devido às complicações. O mesmo tinha anteriormente uma vida sexual normal e um tamanho de pênis normal. Conclui que a maioria daqueles homens tem problemas psicológicos que as cirurgias não resolvem. Moreira (apud ISIR, 2000, p. 23) afirma que os pacientes apresentam uma dismorfofobia peniana e que não há indicação para cirurgia, a solução seria uma terapia psicossexual. Menciona também resultados estéticos catastróficos da cirurgia e desaconselha os tratamentos por serem atos dúbios para o paciente e eticamente reprovados do ponto de vista médico.

Pryor (apud ISIR, 2000, p. 23) realiza as operaçōes em homens com micropênis, menos de $8 \mathrm{~cm}$ de comprimento e os resultados podem ser espetaculares, porém, atualmente os homens que têm uma genitália normal, raramente são operados. Indica “[...] consentimento informado para eles, porém, percebe que esses homens tem convicções muito firmes em relação a necessidade 
cirúrgica e nada consegue pará-los. O conselho psiquiátrico é igualmente inútil e a operação raramente preenche suas expectativas”.

Vanderschueren (apud ISIR, 2000, p. 23) pensa que o primeiro passo na comunidade científica é reconhecer o homem com síndrome de pênis curto como uma entidade, o que seria o início para a construção de uma base científica e pensa que devem ser estabelecidas as diretrizes para reconhecer tal síndrome. Levar esses homens a sério é a primeira etapa. E talvez a "comunicação" possa ser nossa ferramenta primária de pesquisa para melhor compreender esses homens.

Slob (apud ISIR, 2000, p. 24) menciona que a cirurgia de alongamento não é executada normalmente por urologistas comuns e que os mesmo só contemplam a possibilidade cirúrgica quando atestado por um psicólogo clínico um sofrimento psicossexual grave. Menciona que Kropman (ibid, 2000, p.22) executaram a cirurgia em 16 pacientes e após um seguimento de 13 a 50 meses, média 36 meses, obtiveram em 15 pacientes os seguintes resultados: 5 satisfeitos, 3 um pouco satisfeitos e 7 insatisfeitos. Os autores concluíram que a cirurgia pode ser benéfica em alguns pacientes, porém sugerem que $\mathrm{o}$ aconselhamento para melhorar a imagem corporal negativa e baixa auto-estima seria preferível na maioria dos pacientes. Concluem que são necessárias mais pesquisas para lançar luz sobre esse assunto e que as clínicas particulares não devem só fazer a cirurgia, mas também cooperar com os pesquisadores e sexólogos para que se obtenha maior número de informação sobre a satisfação a longo prazo de seus pacientes, assim como seus perfis psicológicos.

Podemos observar nestes diferentes posicionamentos de cirurgiōes com larga experiência nas técnicas propostas para aumento de pênis resultados promissores, assim como profissionais que deixaram de fazer os procedimentos por terem obtido maus resultados. Opinam ainda, clínicos e terapeutas a respeito do assunto tratado pareceres ambíguos, em algumas situações de forma favorável e em outras negativamente. Penso que para tratar estes pacientes devemos ter em mente o seguinte:

1. os procedimentos cirúrgicos de aumento de pênis devem ser praticados por profissionais experientes;

2. há uma população que independentemente dos maus resultados inerentes a qualquer procedimento cirúrgico vai procurar ajuda para realização do seu "sonho";

3. o profissional que se propõe aconselhar um paciente com estas queixas, deve ter uma vivência abrangente na clínica sexológica, nas técnicas 
cirúrgicas, nas suas complicações e na sua capacidade para resolvê-las, de preferência acompanhado sempre por uma equipe multidisciplinar;

4. além de que um diagnóstico diferencial será fundamental para o sucesso de qualquer tratamento proposto para estes pacientes.

\section{Referências bibliograficas}

ALTER, G.J. Augmentation Phalloplasty. The Urologic Clinics of North America. 22, 4, p. 887-902, 1995.

ANDRADE-SILVA, M.A. In: ROMERO, A. Da Tragédia ao Prazer Sexual, São Paulo:Scortecci, p.15-17, 2002.

BURMAN, S.O.; KELLY, T.P. Enhancement Phalloplasty with Girth Augmentation by Autologous Fat Transfer: A Further Report of 700 Cases. Proceedings of the International Symposium on Penile Disorders, Germany, p. 252-275, 1996.

CARSON, C.; KIRBY, R.; GOLDESTEIN, I. Textbook of Erectile Dysfunction. Oxford: Isis Medical Media, 1999.

CONSULTA PROCESSUAL: <www.trf1.gov.br>. Acesso em: 10 ago. 2007.

ENCICLOPEDIA DE LA SEXUALIDAD. Barcelona: Oceano Grupo Editorial, 1, p.115, 2002.

FELDMAN, K.W.; SMITH, D.W. Fetal Phallic Growth and Penile Standards for Newborn Male Infants. Journal of Pediatrics. 86, 3, p. 395-398, 1975.

GARAT, J. M. y RUIZ DE TEMIÑO, M. In: MONSENY, J.I.P.; ARRONDO, J.L.A. Práctica Andrológica. Barcelona: Masson-Salvart, 1994.

HINDERER, U. T.; ESPINOSA, J.F. Nueva Técnica de Alargamiento com Aumento del Volumen en la Hipoplasia del Pene, Constitucional o em el Hipospadias. Cirugia Plástica Ibero-Latinoamericana, XXIII, 2, abril-junio, p.151-160, 1997.

HOLANDA, A.B. Dicionário Aurélio Básico da Língua Portuguesa. Rio de Janeiro: Editora Nova Fronteira, 1988.

ISIR - INTERNATIONAL SOCITY FOR IMPOTENCE RESEARCH.

News Bulletin, Issue 4, September, 2000.

MAIZELS, M.; ZAONTZ, M.; DONOVAN, J.; BUSHNICK, P.N.; FIRLIT, C.F. Surgical Correction of the Buried Penis: Description of a Classification System and a Technique to Correct the Disorder. Journal Urology. 136, p.268-272, 1986.

MARZANO, C. Tamanho do Pênis. Merc News. 8, 81, p. 44, 2002. 
MASTERS, W.H \& JOHNSON, V.E. A Resposta Sexual Humana. São Paulo: Livraria Roca, p 158-160. 1984

MONSENEY, J.I.P.; ARRONDO, J. L.A. Práctica Andrológica. Barcelona: Masson-Salvart, p.775, 1994.

ROMERO, A. A Plástica do Sexo. Como Alongar e Aumentar o Calibre do Pênis. Revista Manchete, n. 2109, p. 82-86, Rio de Janeiro, 05 de setembro 1992. 2002.

Da tragédia ao Prazer Sexual. São Paulo: Scortecci, p. 22-23,

Ejaculação Precoce Primaria. Neurotomia e Neurotmese Seletiva dos Nervos do Pênis em Pacientes não Responsivos a Procedimentos Focais Cognitivo Comportamentais para o Desenvolvimento de Biofeedback Sensorial. Rio de Janeiro: UGF. p. 137, 2003.

ROMERO, A.; CANELLA, P.R.B. Testes Especiais no Diagnóstico da Disfunção Erétil. Revista Brasileira de Sexualidade Humana. 14, 2, p. 95-114. 2003.

ROMERO, A.; STIPP, J.R.; GARIBA, M.C.A. Aumento de Grossura Peniana Através de Enxerto Sintético (PTFE). In: VII CONGRESSO NACIONAL DE ANDROLOGIA 2000 UMAANDROLOGIA PARA O SÉCULO XX!, Espinho. Anais. Espinho: Sociedade Portuguesa de Andrologia, p. 85-86, 2000.

ROOS, H.; LISSOOS, I. Penis Lengthening. International Journal of Aesthetic and Restorative Surgery. 2, 2, p. 89-96, 1994.

SANTOS, B.O.F. Evaluation of 136 Surgeries to Enlarge the Pênis. Int. Journal Impotence Reserch. 8. 3. p.36, 1996.

SCHONFELD, W.A; BEEBE, G. W. Normal Growth and Variation in the male genitalia from birth to maturity. Journal Urology, 48, p.759-777, 1942.

STUBBS, R.H. Penis Lengthening - A Restrospective Review of 300 Consecutive Cases. Canadian Journal of Plastic Surgery. 5, 2, p. $93-$ 100, 1997.

WESSELLS, H.; LUE, T. F.; MCANINCH, J. W. Penile Length in the Flaccid and Erect States: Guidelines for Penile Augmentation. Journal Urology, 156, p. 995-997, 1996. 